\title{
Mini- Implant Materials: An Overview
}

\author{
Safiya Sana ${ }^{1}$, Manjunath $\mathrm{G}^{2}$, \\ ${ }^{I}$ Assistant Professor, Department of Orthodontics, Al-Badar Dental college and hospital, Gulbarga, India \\ ${ }^{2}$ Reader, Department of Orthodontics, Al-Badar Dental college and hospital, Gulbarga, India
}

\begin{abstract}
Purpose: The aim of the present investigation was to review and evaluate the current literature on the mini-implants in orthodontics with regard to their materials properties. The ultimate aim of biomaterials as applied to mini-implants is to serve as efficient temporary anchorage devices. The attainment of this objective is dependent upon a complex interplay of material properties, device design, and physiologic requirements. It is the orthodontist's responsibility to understand both the materials and structural limitations of these devices and the principles of application to minimize performance failure. Manufacturers use six different titanium-based biomaterials to fabricate mini implants. Each of these materials, including four grade of commercially pure titanium and two titanium alloys and 316L Stainless steel used as a mini implant materials each has distinct mechanical and physical properties. Clinician should recognize these differences for to minimize performance failure and patient care.
\end{abstract}

Key Words: Biomaterials, corrosion, mini-implants, stainless steel, titanium, titanium alloys

\section{Introduction}

Conventional dental implants are efficient as anchorage devices in orthodontics. ${ }^{1}$ In 1997, Wehrbein et al tested short titanium (Ti) screw implants in the maxilla for orthodontic anchorage in Germany. ${ }^{2}$ In the same year, in Japan, Kanomi used mini-implants to anchor orthodontic movements. ${ }^{3}$ The use of miniscrew implants in orthodontics for enhancing anchorage has progressed in recent years, with many applications involving retraction of anterior teeth, correction of open bites, distalization and intrusion of teeth. Even though it has been more than 10 years since the first reports on this anchorage system, most evidence is still in case reports or case follow-up studies, with only a few articles dealing with basic material properties. ${ }^{4,5}$

The major groups of implantable materials for dentistry are titanium alloys, cobalt chromium alloys, austenitic Fe-Cr-Ni-Mo steels, tantalum, niobium and zirconium alloys, precious metals, ceramics, and polymeric materials. ${ }^{6}$ Miniscrew implant manufacturers have adopted materials from the broader area of dental implants, including commercially pure (cp) titanium (Ti) and Ti alloy (Ti6Al4V). ${ }^{5,6}$ Although evidence on miniscrew composition is rare in the literature, many clinicians recognize only two types of titanium implant biomaterials: commercially pure (cp) titanium and titanium alloy. Among these two general groups, however, are six distinct materials defined by the American Society for Testing and Materials (ASTM). All six of these titanium materials, which include four grades of cp titanium, two titanium alloys, and stainless steel are commercially available. The mechanical and physical properties of these materials differ significantly. ${ }^{7}$ This review focuses on these physical properties and also evaluates their impact on the primary stability and success of Temporary anchorage devices.

\section{History of Implant Materials}

The first evidence of the use of implants dates back to $600 \mathrm{AD}$ in the Mayan population. They used fragment of a mandible as the implant to replicate three lower incisor teeth. ${ }^{6}$ In 1809, Maggiolo described the process of fabricating and inserting gold roots to support teeth. The implant was constructed from three pieces of gold that were soldered together in the approximate proportion of the socket created by the extraction of the tooth that it would replace. This could be considered as the predecessor of the present-day implant in its modern form having multiple applications for varied purposes, ranging from providing tooth replacement to absolute anchorage for tooth movement. ${ }^{6}$ Greenfield, ${ }^{8}$ in the patent of 1909 entitled "Mounting for Artificial Teeth", envisioned a replacement for teeth, the basis of which was a metal frame that would be inserted into a cavity drilled into the jaw bone. ${ }^{8}$

According to Strock, ${ }^{9}$ the iridioplatinum mesh work of Greenfield ${ }^{8}$ was not strong enough to withstand the forces placed on it. At that point in time implants were frequently made of Lead and Iron, which eroded intra-orally and also caused bone resorption. Strock began to use the screw principle of fixation combined with recently developed alloy called Vitallium, which Venable and Stuck had determined to be completely inert. It was not until late 1950s that Per Ingar Branemark came onto scene. It was then that this researcher was using specially designed optimal titanium screws, which undergo osseointegration. ${ }^{10}$ The first clinical report in the literature of the use of TADs appeared in 1983 when Creekmore and Eklund ${ }^{11}$ used a 
vitallium screw to treat a patient with a deep impinging overbite. ${ }^{11}$ This technique did not gain immediate acceptance due to the lack of the acceptance of surgical procedures, the still unaccepted field of implant dentistry, lack of scientific data on the use of implantable materials, and the fear of complications. ${ }^{12}$ The currently available temporary anchorage devices can be classified as either biocompatible or biological in nature. Both groups can be subclassified based on the manner in which they are attached to bone, either biochemical (osseointegrated) or mechanical (cortically stabilized). ${ }^{12}$

For purposes of understanding this article is divided into three sections: the ideal requirements of mini-implant materials, the specific implant materials currently used, and comparison of mechanical properties of miniimplants materials.

\subsection{Ideal Requirements Of Mini- Implant Materials}

The material must be nontoxic and biocompatible posses' excellent mechanical properties, and provide resistance to stress and strain, resistance to corrosion. The materials used for implants can be broadly divided into 3 categories

1. Biotolerant: - Material that is not necessarily rejected but are surrounded by fibrous layer in the form of a capsule. Eg. Stainless Steel, Chromium-Cobalt Alloy

2. Bioinert: - Material that allows close apposition of bone on their surface, leading to contact osteogenesis. Eg. Titanium, Carbon

3. Bioactive: - Materials that allow formation of new bone onto their surface, but ion exchange with host tissue leads to formation of a chemical bond along the interface (bonding osteogenesis). Eg. Vetro ceramic apatite hydroxide, Ceramic oxidized aluminum. ${ }^{6,13}$

\subsection{Specific Mini-Implant Materials}

\section{Stainless Steel}

The primary stainless steel alloy presently recommended for device manufacture is the American Iron and Steel Institute (AISI) type 316L. Type 316 (low Carbon) Austenitic Stainless Steels contains 10-14\% of Nickel, $2-3 \%$ of Molybdenum, $16-18 \%$ of Chromium and a maximum of $0.03 \%$ of carbon. ASTM recommends type 316L for implant fabrications for the obvious reason that presence of less carbon decreases the chance of forming chromium carbide that generally results in intergranular corrosion. Lowering of the carbon content also makes this type of stainless steel more corrosion-resistant to chlorine-bearing solutions such as physiological saline in the human body. ${ }^{14,15}$ To maintain the specified austenitic microstructure, the normal hardening and tempering heat treatments of carbon-and low-alloy steels cannot be performed. Indeed, within the composition and phase specifications of 316L, hardening can be achieved only by a process known as cold-working. Coldworking can produce a twofold to threefold increase in yield strength, a $40 \%$ increase in ultimate strength, but a corresponding $80 \%$ decrease in ductility, thus making the material far more brittle. ${ }^{15}$

\section{Cobalt- chromium alloys.}

Two main types of cobalt-based alloys are used for surgical implant purposes; a cast alloy and a wrought alloy, which vary significantly in composition. Despite these differences, however, the trade designation of Vitallium (or in Britain, "Stellite") is often applied erroneously to both alloys. The cobalt-based alloys display a useful balance between mechanical properties and biocompatibility, both forms being somewhat superior to stainless steel in strength and corrosion resistance but more expensive to manufacture. Co-Cr alloys are hardly used as mini-implant materials. ${ }^{15}$

\section{Titanium and Its Alloys}

American Society for Testing and Materials (ASTM) has classified commercially pure titanium into different grades. There are five unalloyed grades of commercially pure Ti grades I, II, III, IV and V (Table I), based on concentration of iron (0.2-0.5 wt \%) and oxygen (0.18-0.40 wt \%). Other impurities include nitrogen $(\mathrm{N})$, carbon $(\mathrm{C})$ and hydrogen $(\mathrm{H})$.

Four possible types of titanium alloys can be produced: alpha, near alpha, alpha - beta and beta $(\beta)$ on the basis of their microstructure. Alpha $(\alpha)$ alloys essentially have an all-alpha microstructure and no $\beta$ phase on cooling. $18,19,20,21$ 
Chemical composition, \% max of commercially pure titanium. ${ }^{7,16,17}$ (Table I)

\begin{tabular}{|l|l|l|l|l|l|}
\hline Designation & N & C & H & O & Fe \\
\hline ASTM Grade 1 & 0.03 & 0.10 & 0.015 & 0.18 & 0.20 \\
\hline ASTM Grade 2 & 0.03 & 0.10 & 0.015 & 0.25 & 0.30 \\
\hline ASTM Grade 3 & 0.05 & 0.10 & 0.015 & 0.35 & 0.30 \\
\hline ASTM Grade 4 & 0.05 & 0.10 & 0.015 & 0.40 & 0.50 \\
\hline
\end{tabular}

An alpha alloy will basically comprise of titanium that is commercially pure titanium with alpha stabilizing elements added such as aluminum, nitrogen, and oxygen. ${ }^{18,21}$ Addition of aluminum to titanium increases the tensile strength, creep strength and elastics modulus and also will expand the $\alpha$ phase and increase the strength. ${ }^{19,20}$ The mechanical properties of alpha titanium can be altered using different cooling rates after annealing at temperatures higher than that required for alpha to beta phase transformation. These cooling rates can produce structures with varying grain morphologies and therefore produce titanium with variable strengths. With $\alpha$ phase alloys, the presence of minimal amounts of interstitial elements such as hydrogen, nitrogen, oxygen and carbon can affect the mechanical properties in much more distinct manner. Titanium produces detectable embrittlement due to precipitation of titanium hydride when the alloy is slow cooled in alpha phase region [for ex. $400^{\circ} \mathrm{C}$ ]. ${ }^{17}$ The alpha phase alloy most commonly examined is commercially pure titanium. Commercially pure titanium along with other near alpha alloys exhibit best corrosion resistance, but it lacks strength. ${ }^{18}$

A beta-stabilized ( $\beta$ alloy) titanium alloy will have vanadium, molybdenum, iron, chromium and zirconium added to stabilize the phase. ${ }^{18}$ It has higher yield and ultimate tensile strength than all alpha-alloys. Alpha-beta alloys have a composition of a mixture of alpha and beta phases and $10-50 \%$ of $\beta$ phase at room temperature. ${ }^{17}$ One of the most successful alpha-beta alloys is Ti-6Al-4V, which has an excellent combination of strength, toughness and corrosion resistance. ${ }^{17,21}$

\subsection{Comparison of Mechanical Properties Of Cp Titanium, Titanium Alloys And Other Alloys}

To determine the optimum factor of safety for mini screw implants, the variations of mechanical properties and deterioration, such as fatigue by continuous bending stress during tooth movement and corrosion in oral environment, should be considered. The factor of safety for a mini screw is in inverse proportion to its diameter. The strength of titanium or any other alloys depends on its microstructure, which is influenced by composition, heat treatment and machining process of the mini screws implants. ${ }^{21}$

The mechanical properties of titanium, titanium alloys and other materials are listed below in Table II $^{7}$

\begin{tabular}{|l|l|l|l|l|l|}
\hline Materials & $\begin{array}{l}\text { Modulus of } \\
\text { elasticity (Gpa) }\end{array}$ & UTS (Mpa) & $\begin{array}{l}\text { Yield strength } \\
(\mathrm{Mpa})\end{array}$ & Elongation (\%) & Density (g/cc) \\
\hline Cp grade I Ti & 102 & 240 & 170 & 24 & 4.5 \\
\hline Cp grade II Ti & 102 & 345 & 275 & 20 & 4.5 \\
\hline Cp grade III Ti & 102 & 450 & 380 & 18 & 4.5 \\
\hline Cp grade IV Ti & 104 & 550 & 483 & 15 & 4.5 \\
\hline Ti-6Al-4V ELI & 113 & 860 & 795 & 10 & 4.4 \\
\hline Ti-6Al-4V & 113 & 930 & 860 & 10 & 4.4 \\
\hline Co-Cr-Mo & 240 & 700 & 450 & 8 & 8.5 \\
\hline 316L steel & 200 & 965 & 690 & 20 & 7.9 \\
\hline Cortical bone & 18 & 140 & n/a & 1 & 0.7 \\
\hline Enamel & 84 & 10 & n/a & 0 & 3 \\
\hline
\end{tabular}

Comparing the mechanical properties (Table II) it is important to note that while the modulus of elasticity of $\mathrm{cp}$ grade I titanium to $\mathrm{Cp}$ grade IV titanium ranges from 102-104 GPa, the yield strength increases from 170 to 483 MPa (a gain of 180\%). The reasons for such change are chiefly related to oxygen residuals in metals (Table 1). The characteristics trend of increasing strength with relatively constant modulus continues when comparing $\mathrm{Cp}$ titanium with titanium alloys. The modulus of elasticity of alloys is slightly higher (113 MPa compared to 104 MPa of Cp grade IV titanium), but the yield strength increases over $60 \%$ to $795 \mathrm{MPa}$ for ELI alloys (Ti-6Al-4VELI are designed both to resist stress corrosion in aqueous salt solutions and for high fracture toughness.) and $860 \mathrm{MPa}$ for Ti-6Al-4V alloys. Typically, fatigue strength is less than $50 \%$ of the ultimate tensile strength (UTS) ${ }^{7,18}$ 
A study was done by Lijima et al to investigate torsional properties and microstructure of 4 different commercially available titanium miniscrews. 4 brands of miniscrews selected (AbsoAnchor, Dentos; OSAS, Epoch Medical Corp; BIODENT Co, LTD; Dual Top, Jeil Medical Corp.) A-D with 1.6mm diameter was compared. The results showed miniscrew A and $\mathrm{C}$ implants were pure titanium (equiaxed alpha titanium), whereas B and D contains small globular particles of beta titanium in a matrix of alpha titanium, Only $\alpha$ titanium peaks were detected for all implants by micro x-ray diffraction, but beta-titanium was observed in the microstructures of B and D implants, which had significantly higher torsional moments at failure. ${ }^{21}$ Yokoyama et al opined that alpha titanium in the biological environment absorbs hydrogen and this may be the reason for delayed fracture of the titanium implants owing to the formation of Titanium hydride, over a period of time in the presence of moisture. ${ }^{22,17}$

Compared with Co-Cr-Mo alloys, titanium alloys is almost twice as strong and has half the elastic modulus. Compared to 316L stainless steel, the Ti-6Al-4V alloys are roughly equal strength, but it has half modulus. ${ }^{7}$ So titanium devices have the advantage over stainless steel as they have high bioactivity and more flexibility that improve integration and mechanical fixation. Because screw geometry and materials composition are significant factors in the screws biomechanics, altering these items could change the screw's mechanical strength $^{23}$. The strength is beneficial because materials better resist occlusal forces without fracture or failure. Lower modulus is desirable because the material better transmits forces to bone. This property leads to more even distribution of stress at critical bone-implant interface because the bone and implant will flex in a more similar fashion. ${ }^{7}$ Although fracture at the neck of the mini screw implant is often experienced under clinical conditions, it is largely influenced by the design of the implant. ${ }^{23}$

Sufficient mechanical strength is needed for implants used in orthodontics to resist torsional stresses developed at the screw threads during clinical placement and removal. ${ }^{21}$ The forces associated with placement and removal can cause miniscrew failure, especially if partial integration has occurred. For this reason, in more mineralized tissue, the tension applied on rotation may reach their breaking point. This also applies when the screws are removed, especially in the mandibular bone which is more mineralized than maxillary bone. The tendency to manufacture screws with a reduced diameter could have led to a dangerous reduction of their mechanical resistance. ${ }^{23}$ Torsional properties of stainless steel screws are different from titanium screws. Stainless steel bone screws are easier to handle because the surgeon can feel the onset of plastic deformation and this provides adequate pre-warning to avoid over-torquing the screw while titanium screws break suddenly. ${ }^{24,25}$ An investigation was done by Carano et al ${ }^{23}$ to evaluate the mechanical properties of three commercially available self-tapping screw systems used in orthodontic treatment. The three systems are namely Leone (surgical stainless steel), Dentos (titanium grade IV), M.A.S (titanium grade V). The result showed that all three miniscrews have shown values that give them enough resistance to failure during insertion, application, and removal in orthodontics. Although stainless steel has demonstrated to be more resistant to failure than titanium, its overall performance as material for miniscrew could be inferior to titanium.

\subsection{Comparison of Corrosion Properties of Cp Titanium and Other Alloys}

One of the reasons for the failures of dental implant is corrosion. Therefore the choice of the materials used for implant as well as implant borne suprastructures becomes crucial. ${ }^{22}$ Biomedical materials which are subjected to cyclic loading and high stresses in the presence of aggressive environment fail due to fatigue. Fatigue process is found to get further accelerated due to the formation of wear debris leading to fatigue wear. During fatigue there is disruption of the oxide layer and the inability of the material to repassivate immediately exposes some region of the metal to the environment leading to corrosion. ${ }^{26,27}$ Corrosion can severely limit the fatigue life and ultimate strength of the material leading to mechanical failure of the implant. ${ }^{22}$

The excellent corrosion resistance of titanium and its alloys results from a very stable, continuous highly adherent and protective oxide film on metal surfaces. In most aqueous environments the oxide is typical i.e. $\mathrm{TiO}_{2}$, but may consist of mixtures of other titanium oxides, including $\mathrm{TiO}_{2}, \mathrm{Ti}_{2} \mathrm{O}_{3}$ and $\mathrm{TiO}$ known as Rutile and Anatase. ${ }^{28} \mathrm{TiO} 2$ is highly chemically resistant. This is one contributing factor for high biocompatibility of $\mathrm{cp}$ titanium and its alloys. ${ }^{29}$ Commercially pure titanium is widely used as implant material because of suitable mechanical properties and excellent biocompatibility. However, cp Ti has lower fatigue strength than titanium alloys (Ti-6AL-4V). Ti-6AL-4V can be used to overcome this disadvantage. However, corrosion resistance of the mini-implants decreases when alloy is used, favoring metal ion release, which may be associated with clinical implant failure, osteolysis, cytotoxicity etc. ${ }^{21}$ In contrast, a study done by Morais et al, detected concentrations of Vanadium which did not reach toxic levels in the animal model. ${ }^{30}$

ASTM recommends type 316L for implant fabrications because the presence of less carbon decreases the chance of forming chromium carbide that generally results in intergranular corrosion. Lowering of the carbon content also makes this type of stainless steel more corrosion-resistant to chlorine-bearing solutions such 
as physiological saline in the human body. ${ }^{2}$ However stainless steel is susceptible to localized corrosion by chloride ions and reduced sulfur compounds. ${ }^{31}$

Nickel is present in Stainless steel in a concentration of $10-14 \%$, recent evidence has attributed carcinogenic, mutagenic, cytotoxic, and allergenic - actions to $\mathrm{Ni}$ in various forms and compounds. Investigators have recognized the potential biological implications of nickel release, focusing on the fate of corrosive products of alloys used in orthodontics. ${ }^{32}$

In general passive film formation on titanium-containing alloys is more stable than its chromium counterpart in stainless steel alloys, especially in chloride ion rich environments. ${ }^{33}$

\section{Conclusion and Clinical Implication}

Elastic modulus, strength and biocompatibility are important consideration in choosing an orthodontic miniscrew material. The material chosen should have sufficient mechanical strength to resist the torsional stresses developed at the screw threads during clinical placement and removal without permanent deformation. It should also have a low modulus for optimum force transfer to bone.

Commercially pure $\mathrm{Ti}$ (cp Ti) is the most used material in implantology because of its proven biocompatibility with human tissues, high corrosion resistance in body fluids, lack of allergenicity, high specific strength, and low elastic modulus when compared with other metallic biomaterials. Nevertheless, orthodontic mini-implants are smaller than conventional dental implants and must bear high orthodontic loads. These factors contribute to the possible fracture of $\mathrm{cp} \mathrm{Ti} \mathrm{mini-implants} \mathrm{during} \mathrm{placement} \mathrm{and} \mathrm{removal.} \mathrm{To} \mathrm{overcome} \mathrm{this} \mathrm{disadvantage,} \mathrm{Ti}$ alloy implants, made with aluminum $(\mathrm{Al})$ and vanadium $(\mathrm{V}),(\mathrm{Ti}-6 \mathrm{Al}-4 \mathrm{~V})$ for greater strength and fatigue resistance than $\mathrm{cp} \mathrm{Ti}$, are required.

\section{References}

[1] Morais LS, Serra GG, Palermo EFA, Andrade LR, Muller CA, Meyers MA, Elias CN. Systemic levels of metallic ions released from orthodontic mini-implants. Am J Orthod Dentofac Orthop 2009;135:522-529

[2] Wehrbein H, Glatzmaier J, Yildirim M. Orthodontic anchorage capacity of short titanium screw implants in the maxilla. An experimental study in the dog. Clin Oral Implants Res $1997 ; 8: 131-41$.

[3] Kanomi R. Mini-implant for orthodontic anchorage. J Clin Orthod1997;31:763-7.

[4] Park YC, Lee SY, Kim DH, Jee SH. Intrusion of posterior teeth using mini-screw implants. Am J Orthod Dentofac Orthop 2003;123:690-694.

[5] Eliades T, Zinelis S, Papadopoulos MA, Eliades G. Characterization of retrieved orthodontic miniscrew implants. Am J Orthod Dentofac Orthop 2009; 135:10.e1-10.e7

[6] Rasmussen RA. The Branemark system of oral reconstruction: a color atlas ( Ishiyaku Euro-America Inc; Tokyo, 1992)

[7] McCraden M. Dental implant Materials: Commercially pure Titanium and Titanium alloys. J Prosthod 1999;8:40-43

[8] Greenfield EJ: Mounting for Artificial Teeth. Patent \#943, 113, 1909, pp 1-3. Wichita, Kansas

[9] Strock AE: Experimental work on a method for the replacement of missing teeth by direct implantation of a metal support into the alveolus. Am J Orthod Dentofac Orthop 1939;25:467-472.

[10] Branemark PI: Osseointegration and its experimental background. J Prosthet Dent. 1983; 50:399-410.

[11] Creekmore TD, Eklund MK: the possibility of skeletal anchorage. J Clin Orthod 1983; 17:266-269

[12] Cope JB. Temporary Anchorage Devices in Orthdontics: A Paradigm Shift. Semin Orthod 2005;11:3-9

[13] Huang HL, Shotwell JL, Wang HL. Dental implants for orthodontic anchorage. Am J Orthod Dentofac Orthop 2005;127:713-722

[14] Graber Vanarsdall Vig. Orthodontics Current Principles \& Techniques(Fourth Edition Elsevier publication), p.no. 357-365

[15] Smith GK. Orthopaedic Biomaterial: http://cal.vet.upenn.edu/projects/saortho/chapter_13/13mast.htm. Accessed on 6/02/2013

[16] Wang RR, Fenton A. Titanium for prosthodontics application: a review of literature. Quintessence Int 1996; 27: 401-408.

[17] James D.Destefani. Introduction to titanium and titanium alloys ( Metals handbook $9^{\text {th }}$ ed. American Society for metals) pp 586663.

[18] Donachie MJ. Titanium: A technical guide. American Society for Metals; Metals Park OH $159,162 \& 353$.

[19] Kanie T, Nagata M, Ban S. Comparison of the Mechanical Properties of 2 Prosthetic Mini-implants. Implant Dent 2004;13:251-256

[20] Parr GR, Gardner LK, Toth RW. Titanium: The mystery metal of implant dentistry. Dental materials aspects. . J Prosthet Dent. $1985 ; 54: 410-414$.

[21] Lijima M, Muguruma T, Brantley WA, Okayama M, Yuasa T, Mizoguchi I. Torsional properties and microstructure of miniscrews implants. Am J Dentofac Orthod 2008; 134:333.e1-333.e6.

[22] Charturvedi TP. An overview of the corrosion aspects of dental implants (titanium and its alloys). Indian J Dent Res 2009;20(1):9198

[23] Carano A, Lonardo P, Velo S, Incorvati C. Mechanical properties of three different commercially available miniscrews for skeletal anchorage. Prog Orthod 2005; 6(1):82-97.

[24] Disegi JA, Eschbach L: Stainless steel in bone surgery. Injury 2000. 31 (Suppl 4): 2-6.

[25] Disegi JA, Wyss H: Implant materials for fracture fixation: a clinical perspective. Orthopedics 1989. 12:75-79

[26] Park JB. Biomaterials science and engineering. Plenum.( New York: Wiley-Liss 1984) pp. 193-233.

[27] Kamachi MU, Baldev R. Corrosion science and technology: mechanism, mitigation and monitoring.9 UK: Taylor \& Francis 2008) pp. 283-356.

[28] Ronald Schutz, David Thamas. Corrosion of titanium and titanium alloys. Metals Handbook $9^{\text {th }}$ ed. 669-706. American Society for metals.

[29] Kasemo B. Biocompatibility of Titanium implants: surface science aspects. J Prosthet Dent 1983;49(6):832-837

[30] Morias LS, Serra GG, Mullar CA, Andrade LR, Palermo EF.A, Elias CN, Meyers M. Titanium alloy mini-implants for orthodontic anchorage: Immediate loading and metal ion release. Acta Biomaterialia 2007 ; (3):331-339. 
[31] Ismail KM, Jayaraman A, Wood TK, Earthman JC. The influence of bacteria on the passive film stability of 304 stainless steel. Electrochim Acta 1999; 44: 4685-4692.

[32] Eliades T, Athanasios E. In Vivo Aging of Orthodontic Alloys: Implications for Corrosion Potential, Nickel Release, and Biocompatibility Angle Orthod 2002; 72: 222-237.

[33] Eliades T, Pratsinsis H, Kletsas D, Makou M. Characteriszation and cytotoxicity of ions released from Stainless steel and Ni-Ti orthodontic alloys. Am J Orthod Dentofac Orthop 2004;125:24-9 